\title{
Designing Practical Teaching System for Outside-school Practice Base
}

\author{
Tiefeng Wang ${ }^{1, a}$, Ying Cai ${ }^{1, b}$, Meie Shen ${ }^{1, c}$ and Chengxia Liu ${ }^{1, d}$ \\ ${ }^{1}$ Computer School, Beijing Information Science and Technology University, 100101, China \\ awangtiefeng@bistu.edu.cn, bbycai@bistu.edu.cn, smllk@163.com, diucx@bistu.edu.cn
}

Keywords: practical teaching system architecture; teaching content design; black box testing.

\begin{abstract}
A great deal of department in enterprise how to optimize practicing-teaching contents, and forms the practicing-teaching system, in building Beijing level Talent training base of outsideschool. The system consist of three parts which is the cognitive course content design, the hardware practice course content design and the software test theoretical teaching content design. We improved concepts, formed a detail enterprise practice curriculum program, and do it in practice. This practice teaching system is a featured program of our university. It has been carried out for 5 years, improving students' engineering and practice skills and therefore fostering eligible persons with various abilities and qualities for the development and prosperity of our country.
\end{abstract}

\section{Introduction}

Enterprise practice is an important practice teaching in the Undergraduate program that students to integrate theory with practice, independent thinking and analytical and problem-solving skills, especially the irreplaceable role in the foster engineering awareness, improve the comprehensive practical ability [1]. This shows that the importance of teaching experiment. And we must carefully design the practice content so that the theoretical teaching and practical teaching to echo each other, complement each other, to enlighten students the wisdom and to stimulate the enthusiasm of students learning practice in order to improve the quality of teaching practice [2-3]. Practice base construction is becoming popular. Especially building the practice base with enterprise is encouraged by the state. There are some activities to evaluate such municipal training base outside in the past two years in Beijing. The goal of these activities is to strengthen students' practical ability and experience. As a representative of the Beijing University of Information Technology, computer school practice base was one of selection for reviewing, has been identified as the one of the training base of Beijing municipal level talent. Many problems involved in off-campus practice bases, how to choose the enterprises, cooperative model, practice management, funding in place, traffic accommodation and mutual benefit. In terms of students, the most important thing is to internship teaching content for practice teaching selection which is determined the core issues including students' practical interest, practice ability and effects of internships. In this paper our contribution are as following.

- To capture the complicated practice process in the university, we develop a practice teaching framework.

- We further optimize practice teaching practicing content and the formation of practiced teaching system which also enable an accurate experience to improve the quality of undergraduate.

- We improved concepts, formed a detail enterprise practice curriculum program, and do it in practice. This practice teaching system is a featured program of our university. It has been carried out for 5 years, improving students' engineering and practice skills and therefore fostering eligible persons with various abilities and qualities for the development and prosperity of our country.

\section{Background}

Beijing Information Science and Technology University (formerly Beijing Information Technology Institute) in 1978 to set up Computer Software major and the Computer and the Application of major which were merged into Computer Science and Technology in 1998. Computer-related professional enterprises can be divided into software design and hardware manufactures. It is unlikely to conduct effective training for software Design Company in large quantities in a short period of time to the 
student. And it is now mostly used large-scale production methods for hardware manufacturing companies that the cultivation of the internship students will mostly keep the tutorial stage and because some impact not well for the implementation the practical internship [4]. With the constant expansion of enrolment, the limitations of off-campus practice sessions become more and more prominent [5]. Due to the rapid development of the modern industry, industry characteristics and corporate confidentiality and other reasons, students do not have opportunities to practice and cultured the ability to identify and solve practical problems. So the students can only take a passive to see and hear. And it is difficult to mobilize the initiative of the students and creativity [6].It is a common problem, but also the most difficult problem that many institutions choose to visit and have a lecture in a meeting room by the enterprise. To avoid this phenomenon from happening, the teachers of the bases survey a number of enterprises including teaching content and conditions. We work hard and ultimately determine the best joint venture - China Electronics Technology Group Corporation the fifteenth Institute (hereinafter referred to as No.15). The companies jointly develop internship programs with us and form an internship teaching system. We get a better solution on this issue and make a good effect. The practical ability of the students is improved.

\section{Optimization Practice Teaching Content and the Formation of Practice Teaching System}

We build a ladder progressive structure of the practice teaching system according to the cognitive law which is "practice, understanding, again practice, and then understanding". The system consists of four steps of cognitive teaching, practice teaching, theory teaching and capacity evaluation. Each step improves one level shown in Fig.1. Each stage contains internship refined as follows. We will describe all contents as more details as follows. The cognitive teaching mainly visit enterprise including the printed circuit board production line processes, the 15th Machinery Factory of advanced CNC machine tools and the National Computer Quality Inspection Center laboratory.

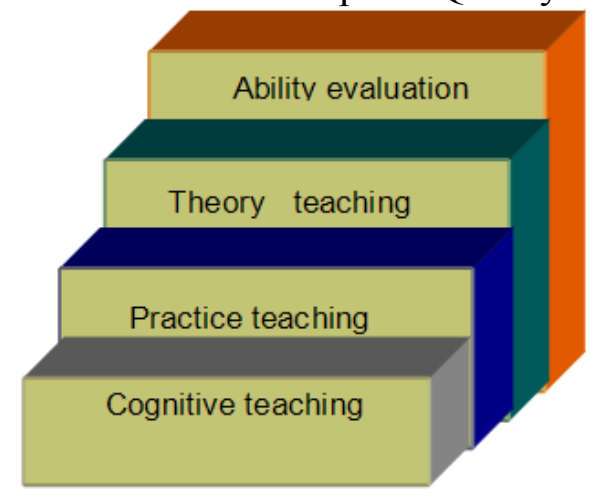

Fig.1. Internship teaching architecture.

The cognitive teaching mainly visit enterprise including the printed circuit board production line processes, the 15th Machinery Factory of advanced CNC machine tools and the National Computer Quality Inspection Centre laboratory.

The main work of the practice teaching includes electrical equipment production; the students assemble the actual product by themselves and the black box testing with certificate.

The contents of lecture include laboratory evaluation of third-party software test technical and management requirements, software testing techniques.

The ability evaluation includes the students' ideological, black box testing certification, understanding of the community and corporate culture etc.

We conduct the optimization of the practice of teaching content and the formation of teaching system by surveying a large number of enterprises and exploring the requirements. We derive a internship teaching system after running the two years. In the following we describe the program design process.

Design of Cognitive Teaching Content. We general arrange production practice for a junior in the second semester because the students master a certain amount of practical ability through experimental course, curriculum design, and open lab projects for the years, but they know very little 
about the actual situation of the enterprise. So the first step in production practices is to conduct cognitive teaching, that is, to visit. No.15 institute is a computer comprehensive enterprise which is a broad range of related computer business and can offer the internships rich contents such as many research groups which are involved the national projects. The PCBA center mainly offer the production service for the aviation, aerospace, defense weapons and equipment production and "Shenzhou" spacecraft etc. And its quality inspection center on behalf of the State to exercise the computer quality testing and there are many other test items. Its mechanical factory does a variety of command center console and irregular shaped cabinet. General tutorial in all departments need at least three whole days and the PCBA center can be used as students of electric and electronic professional internships throughout the production process. So we must design a reasonable program.

We only see the partitions, desks, file cabinets and computer if we visit them the institutes though they do many national and ministerial projects in the research department. The core content are stored in the computer software which is no visual effect to visit the inevitable. So we have to go the conference room to give lectures to explain more details and try to avoid the situation that is most likely to fall asleep in the form of one of the circumstances listed above.

For example, the inspection Laboratory is divided into two categories including software and hardware. We just survey the hardware laboratory which focuses on the embedded Research Laboratory inspection discard the software class laboratory because of above reasons. We seriously choice embedded laboratory in light of it is hot up in recent years and we have offer this course. So it is extensive. Embedded Laboratory of ongoing projects is really advanced in the field of embedded applications. But after in-depth discussion, we find that is not too large difference between visiting Embedded Research Laboratory and other software. There is more drawings and a few samples in here and the details content need to explain in the conference room. We have to give up here in order to improve the practice teaching effect.

Survey the quality supervision and inspection center of national computer. Because The centre has a variety of national supervision and inspection qualification which is mainly responsible for the computer, computer peripherals, computer network equipment, fiscal cash registers, the second generation resident ID card reading equipment, IC card reader, the electronic tag reader, Performance validation and product testing room equipment, satellite digital television receivers. As well as it has software evaluation, computer room engineering, information engineering inspection etc. And at the same time it the electronic product quality arbitration inspection.

The internship program should be relative to actual engineering or life which let students enhance the use of theoretical knowledge and stimulate the students' motivation in depth [1]. Each laboratory in the quality inspection center sees a specific product in the test including the computer and most of the other products which is also often met with in our lives. The staff introduce content, data, parameters and principles in the detection process that make the students and teacher feel emotion, experience, opened the eyes.

For example, the unique structure of radiation harassment testing room is very attractive, plus on-site visit to the factory for inspection computer products, radiation detection process, is even more intriguing, can detect mobile phone radiation of the hot issues, in short, It is a good visit programs.

Another example, the physical characteristics of the IC card detection of the detection chamber, the test, including the distorting force test, the bending force test, the dynamic bending force test, peel test (i.e. adhesion of the film on the card), the mechanical strength test, static test (IC card 2000 Volts), bus card 6000Volts), functional and electrical characteristics test, printing fastness test, electromagnetic fields and ultraviolet test. The students and teacher never know IC card need go through so many tests though we often use it. So it is a good experience.

There are more than 20 tests content like this that can touch students' cognitive processes, and increase the perceptual knowledge, stimulate the desire to explore. We decide that a cognitive curriculum include this 20 more than 20 tests content in the later cognitive teaching content. The actual production practice results prove that the students like this part content and reflected it in their written internship report. 
The students know well the computer's motherboard, graphics card board NIC card board and the PCB but they don't know its production process and process technology. So we have to make up this content for the students. No.15 institute has the PCBA Center, and has been fourth year's reputation. The PCBA center can make a variety of printed circuit board, such as conventional rigid printed circuit board, microwave printed circuit board, flexible and rigid-flex printed circuit board, heat printed circuit board, buried bland hole vies printed circuit board, and high temperature printed a dozen boards etc. They use respectively for different occasions. There are some other good contents such as double-sided printed circuit board manufacturing processes: cutting $\rightarrow$ drilling hole $\rightarrow$ hole $\rightarrow$ dry imagine in the sun $\rightarrow$ Plating $\rightarrow$ etching $\rightarrow$ semi-seized $\rightarrow$ hinder $\rightarrow$ Leveling $\rightarrow$ character $\rightarrow$ milling outside type $\rightarrow$ Flying Probe Test $\rightarrow$ finished testing $\rightarrow$ packaging steps. And the PCBA center made the manufacture products for national defense, aviation, aerospace, in particular the "Shenzhou" aircraft.

We survey the Machinery Plant in No.15 institute. The main production here is a military vehicle, airborne cabinet and command centre console, especially the command centre console in the broadcast of "Shenzhou" aircraft launch site hall. The first mechanical factory affords a lot of this work. The seemingly simple things have to do more than 30 process including static electric, corrosion and other factors.

It is a good idea to choose 'National quality checking centre', 'PCBA centre' and 'Mechnical facroty' as the cognitive teaching. We have good results in the practice from the reporter that the students wrote for several years. So we have succeeded in this stage.

Teachers on the field trips, research and personal experience to form a consensus on the cognitive teaching "National Quality Supervision and Inspection Centre of PCBA Centre" and "mechanical plant" not only give students the expansion of knowledge, but also in practice, knowledge, again practice, understanding the cognitive law experience to recognize the profound meaning of the level. Harvest a column in the previous report, student internships are reflected, many students wrote that this may be a chance for life. Illustrates the stages of the design of cognitive teaching is successful.

Design hardware practice teaching content. After the teaching contents are confirmed, hardware teaching contents design begins, this part should embody the meaning of re-practice in understanding rules, i.e. "practice, understanding, re-practice, re-understanding". The last content to be confirmed is the internship of electronic equipment production, the primary problems that design process involves is as follows:

Giving up unrealistic requirements in front of reality. Since the internship time is limited, it is impossible for one to complete the construction cycle of a hardware production from beginning to the end, the enterprise will not agree either, the content is not compulsory.

Getting totally involved during the stage of real production. This requirement is the hardest one to realize, which most of the enterprises are not able to meet because it's too risky. However, a student will never achieve the goal of internship before he comes to the real production stage. Before the practice base outside school was founded, a hardware internship was designing and making a universal meter. Since the products were not real ones and non responsibility, most universal meters cannot be used, even if the principle, "whoever make the product pays for it himself", was adopted, things were not getting better. Thus, we should carry on thorough communication with enterprise; obtain their trust, so as to achieve our goal.

Choosing the right hardware internship department. After the investigation of the whole institute, we come to a conclusion that it is most suitable to put hardware internship to PCBA centre, the visit contents of which was arranged before. The PCBA itself is able to independently undertake the production internship of the entire Electrical and Electronic major, while students of computer department are participated in just a part of the Electronic equipment production, so it is completely qualified.

Mutual understanding and reaching an agreement. The two sides make a further discussion again, and understand mutual difficulties, then reach an agreement to take students to the stage of Electronic equipment production. At the meantime, both sides assume responsibility for the risk respectively. And of course, students are not allowed to participate in important products. 
Designing course contents of Electronic Equipment Production. The content of the course is designed by advanced engineers instead of teachers. Before the practice begins, lectures given by advanced engineers will present the fundamental knowledge of Electronic Equipment Production to students.

Because of the repeat emphasis on the quality requirements of these equipments, no equipments made by previous students have quality issues, wining the reorganization of the enterprise. Most importantly, students benefit a lot from this program which can be found in their reports about the practice. Experimental project to be classified in accordance with the level of validation, integrated, design innovation and research, internships to training students the practical ability and accumulate the actual practice of the implementation process which is in accordance with the step-by-step process [7].

Design teaching content of software testing theories. Due to the increasing demand of person with software testing experience in the job market, we decide to choose the software testing as an indispensible part of the practice. The Software Testing Center is a good place for students to learn something about software testing, since it has many distinguish software engineers with rich software testing experience. The time arrangement of this program is listed as follow:

Introduction to the third-party software testing centers. This section mainly focuses on the technique requirements of these testing centers, such as general provisions, personnel, facilities and environmental conditions and test methods to confirm equipment, measurement traceability, sampling and samples, the disposal of test samples, test results, quality assurance, and the results of the content.

Course Design of the Methodology of Software Testing. The focus of this section includes White-Box Testing, Black-Box Testing and Gray-Box Testing. We plan to introduce three techniques of White-Box Testing Methodology: Lexical and Syntax Analysis, Static Error Analysis (including type and unit analysis, reference analysis, expression analysis, and interface analysis), as well as Software Stub Technology, and present a detailed summary of Test Plan, Use Case, the Execution of the Test Plan and Test Report of Black-Box Testing Methodology (namely, Functional Tests or Data Driven Testing) to students. For Gray-Box Testing, we only plan to make a simple introduction about it. Based on the feedback and efficiency of previous two years' practice, we reduce the time arranged for the White-Box Testing while increasing the time arranged for Black-Box Testing, since students were more attracted by the Black-Box Testing.

Certification of Black-Box Testing. At the end of the practice, students are required to take an exam of Black-Box Testing. Students have to submit their results within two days. Then, we'll assign each student a score according to the standard procedures to test the ability of testing engineers made by the Quality Testing and Supervising Centre. The exam will not only enhance students' knowledge about Black-Box Testing, but also offer students a precious opportunity to experience it.

The software testing practice is our department's featured program. A large number of students have benefited a lot from this program.

This program not only enhances students' knowledge about software testing, but also empowers eligible students with the national level certification of the software testing ability. The Proportional of final practice score is Quality is more than $70 \%$ and the excellent is $18.5 \%$. The more details are shown in TABLE I. The practice teaching system will enable students to learn more about the entire manufacturing procedures of the Printed Circuit Board as well as a lot of management knowledge, cultivating their sense of integrating theories with practice, their ability to verify and enhance their knowledge learned from books, as well as their ability of investigation, researching, analyzing and problem solving. All of these will lay a solid foundation for their future studies. Besides, the software testing program will broaden students' horizon, and enrich them, learning knowledge which couldn't be learned from books. In summary, the practice teaching system will empower students with advanced knowledge about their major and inspire them to engage themselves into the effort of learning and exploration. 
Table 1. Black Box Testing Statistics.

\begin{tabular}{cccc}
\hline Year & Student Numbers & Quality & Excellent \\
\hline 2007 & 278 & 181 & 36 \\
\hline 2008 & 295 & 198 & 42 \\
\hline 2009 & 316 & 218 & 67 \\
\hline 2010 & 329 & 237 & 63 \\
\hline 2011 & 338 & 254 & 75 \\
\hline
\end{tabular}

\section{Concluding}

In this paper, we explored the enterprise practice including the background, related work and design different training content. At the same time we improved concepts, formed a detail enterprise practice curriculum program, and do it in practice. This practice teaching system is a featured program of our university. It has been carried out for 5 years, improving students' engineering and practice skills and therefore fostering eligible persons with various abilities and qualities for the development and prosperity of our country. We hope that this paper can provide others can learn from the experience and assist.

\section{Acknowledgment}

The research is supported by the General program of science and technology development project of Beijing Municipal Education Commission (No.KM201110772013), Beijing Key Laboratory Open Project of Network Culture and Digital Communication (No.5026035413) and the Funding Project for Academic Human Resources Development in Institutions of Higher Learning under the Jurisdiction of Beijing Municipality Grant (No.PHR201007131 and No.PHR201008428)

\section{References}

[1] Liu Huijun, Xiang Bin, Ji Weirong. Reform and Production Practice mode to improve the production quality [J]. Laboratory Research and Exploration, 2008 (11) :130-132.

[2] Wang Qiguang, Li bingwen, Zhao Jiyun. The exploration of Practice Teaching and Ability Cultivation [J]. Laboratory study and exploration, 2004,23 (1) :69-70

[3] Liu Huiying, Wang Yi, Bi Xiaoyi. To strengthen the practice of education and cultivate the students' overall innovative design ability [J]. Laboratory study and exploration, 2006,25 (6) :703-705

[4] Zhang Ge, Shi Yansheng Liu Liqiang. Strengthen school internship bases for practical training applied talents [J]. Laboratory Research and Exploration, 2009 (2) :148-151

[5] Bi Lina Shao Jingling. Exploration the practice Teaching [J]. China Metallurgical Education, 2004 (6): $28-29$

[6] Duan Jiashi, Cao Huixian, Wang Yu et al. American Universities physics experiment teaching and management inspection report [J]. University Physics, 2004 (3) :42-45

[7] Li Chenwei. Computer professionals talent cultivation in perspective [J]. Chinese personnel, 2006 (7) :6-7

[8] Wang Tiefeng, Cai Ying, Wang Youlan, Hao water. Municipal off-campus personnel training base building [J]. Laboratory Research and Exploration, 2010 (10) :137-140

[9] Ou Shengbin, Chen Jun. Explore and practice of professional practice of applied undergraduate institutions to [J]. Laboratory Research an d Exploration, 2011 (10) : 161-165. 